\title{
Medical Care-seeking Patterns Among Women with Diagnoses Associated with Menstrual Syndromes: A Longitudinal Population-based Study
}

Jong Long Guo

National Taiwan Normal University

Tzu Chi Lee

National Taiwan Normal University

Hsiao Pei Hsu

National Yang-Ming University School of Nursing

Chiu Mieh Huang ( $\sim$ chiumiehhuang643@edtamc.cn )

School of Nursing National Yang-Ming University

Research article

Keywords: Medical care-seeking patterns, menstrual syndromes, Traditional Chinese Medicine, Western Medicine

Posted Date: September 30th, 2020

DOI: https://doi.org/10.21203/rs.3.rs-57404/v1

License: (9) This work is licensed under a Creative Commons Attribution 4.0 International License. Read Full License 


\section{Abstract}

Background: This study aimed to explore women's tendency to seek Traditional Chinese Medicine and/or Western Medicine when newly diagnosed with menstrual syndromes, and to identify factors associated with their medical care-seeking behavior.

Methods: Women aged 15 to 50 years with newly diagnosed menstrual syndromes were selected from Taiwan's 2005 National Health Insurance Database. Follow-up was divided into 10 time-periods (1-6, 7-12, 13-18, 19-24, 25-30, 31-36, 37-42, 43-48, 49-54 and 55-60 months) after patients' first visits for obstetric/gynecologic care. Patients' tendency for medical care utilization was estimated using Poisson regression. Unadjusted and adjusted relative risks and their $95 \%$ confidence intervals were calculated.

Results: The number of Traditional Chinese Medicine utilization was 0.69, and Western Medicine utilization was 1.75 within six months after the first menstrual syndrome diagnosis. The tendency for Traditional Chinese Medicine utilization increased as follow-up time increased after controlling for potential confounders, while Western medicine utilization decreased gradually as follow-up time increased. Women's age, economic status, infertility, value of prevention, baby delivery and Obstetric/ Gynecologic inpatient histories were significantly associated with their medical care-seeking behavior.

Conclusions: Traditional Chinese Medicine and Western Medicine medical care-seeking patterns are significantly different among women with diagnoses associated with menstrual syndromes. Related factors affecting Medical care-seeking behavior have been explored in this study.

\section{Background}

Many study results have indicated that a large proportion of females of reproductive age experience menstruation-related health issues. For young women, prevalence rates of menstrual symptoms include dysmenorrhea 80.9\% 92.5\% [1, 2]; menstrual bleeding amount 19\% [2]; menstrual syndrome 95.8\% [1, 3, 4]; and premenstrual depression 5.6\%[3], and form premenstrual depression was $5.6 \%$ [3]. It indicated that menstrual syndromes are ones of the most disturbing health concerns for women.

Menstrual syndromes are combined symptoms of dysmenorrhea, heavy menstrual bleeding, premenstrual syndrome, and premenstrual dysphoric disorders, and so on [5]. These syndromes may occur before menstruation, or accompanying menstrual cramps and during the menstrual period itself, and may include physical, psychological and social aspects. Women who experience these syndromes experience noticeably impaired function in their social activities or work-related performance [6]. The impact of the syndromes burden on women's daily activities increases with symptom severity [7]. Consequently, the menstrual syndromes burden may lead to higher direct medical costs associated with increased physician visits and laboratory tests [8], and higher indirect costs through lower productivity at work [6]. The effects of menstrual syndromes are very broad and are not restricted to socio-economic impacts. 
Women who experience menstrual syndromes will seek medical care. Medical care-seeking behavior has been defined as any action undertaken by individuals who perceive themselves to have a health problem and tend to find an appropriate remedy $[2,9]$. The health belief model [10-12] proposes that healthcareseeking behavior is influenced by certain factors, including perceived susceptibility (subjective assessment of risk of developing a health problem), perceived severity (subjective assessment the potential consequences of disease), benefits (the value or efficacy of engaging in a health-promoting behavior to decrease risk of disease), barriers (such as inconvenience, expense, danger, access and discomfort), cue to action (the stimulus needed to trigger the decision-making process to accept a recommended health action), and self-efficacy (confidence in one's ability to effect change in outcomes). All of the above factors are affected by demographic, psychosocial and structural variables.

Traditional Chinese Medicine (TCM) has a long history in the treatment of menstrual syndromes. The World Health Organization (WHO) recognizes TCM as a legitimate medical system, and lists it in the 11th revision of the WHO International Classification of Diseases (ICD). This has helped the popularity of TCM to grow rapidly among people who are seeking alternative healthcare remedies rather than relying on Western Medicine (WM) alone. The combined use of TCM and WM, called pluralistic medical utilization, is a common practice for women with menstrual syndromes in Taiwan. However, research on the utilization of TCM and WM by women with menstrual syndromes is seldom reported, especially longitudinal population-based study is comparatively limited. The present study aimed to investigate medical care-seeking patterns among women with newly diagnosed conditions associated with menstrual syndromes and to identify determining factors associated with their medical care-seeking behaviors. Results of this study may not only help to meet women's healthcare needs, but also contribute to reduce inappropriate medical care use.

\section{Methods}

\section{Data Source}

The National Health Insurance (NHI) program was initiated in Taiwan in 1995 and now covers nearly all Taiwan citizens. The Bureau of $\mathrm{NHI}$ has released all claims data in electronic form to researchers under the National Health Insurance Research Database project (NHIRD). A representative cohort database comprising data of 1 million people in 2005 was randomly selected by the National Health Research Institute (NHRI) for scientific purposes from all beneficiaries. The NHRI reported no significant differences in age, gender, or health care costs between the representative group and all beneficiaries under the $\mathrm{NHI}$ program. For this study, we obtained the complete WM and TCM claim datasets from the NHIRD. The datasets contained the patients' medical visit files, including dates, medical care facilities and specialties, patients' genders, dates of birth, and the four major diagnoses coded in the International Classification of Disease, 9th Revision, Clinical Modification (ICD-9-CM) format.

\section{Study Cohort and Group Identification}


Patient selection included all women diagnosed with menstrual syndromes in 2005 that were coded according to the ICD-9-CM. The included categories were as follows: leiomyoma of uterus (ICD-9-CM codes 218), endometriosis (ICD-9-CM codes 617), symptoms associated with female genital organs (ICD9-CM codes 625, except for 625.6), menstruation disorders and other abnormal bleeding from female genital tract (ICD-9-CM codes 626). All medical visit information was tracked back to 2004 to confirm that these subjects were new patients. Because women may experience menstrual symptoms during their entire reproductive life cycle, women were selected within the age range 15-50 years (risk exposure). Women's first visits to obstetricians/gynecologists/TCM in 2005 were extracted for further analysis. Medical utilization patterns for obstetric/gynecologic (Ob/Gyn) care/TCM were also followed for 5 years after their first visits. Figure 1 shows the patient selection process used in this study.

\section{Study Design and Statistical Analysis}

Categorical variables are presented as percentages, continuous variables as mean \pm standard deviation (SD). Multivariate Poisson regression analysis was used to evaluate the tendency for use of TCM or WM obstetric/gynecologic outpatient visits. Follow-up periods were divided into 10 time-periods after first visits for obstetric or gynecologic/TCM healthcare services (1-6, 7-12, 13-18, 19-24, 25-30, 31-36, 37-42, 43-48, 49-54 and 55-60 months). The outpatient visits were calculated for TCM or WM within each time period. The descriptive variables included TCM or WM outpatient visits, age (15-39, 40-50), residence (urban or rural), insurance premium (proxy of economic status), infertility (Yes, No), baby delivery (Yes, No), Ob/Gyn inpatient (Yes, No) and health prevention practices (Yes, No). Monthly insurance premiums were divided into four levels as follows: Fixed premium and dependents (requiring social welfare support, no stable salary); lower income (less than 20,000 New Taiwan Dollars [NTD] per month); middle income (20,000-39,999 NTD per month); and higher income (40,000 NTD or greater per month). Implementation of health preventive measures, such as health exam, Pap smear, or mammography, represents patient's value of prevention.

Most descriptive variables were considered as time dependent, except for patient residence and insurance premium (measured at baseline); that is, their values were assessed by each time-period, and the dynamic effect of these time-dependent variables on response variables was estimated. The unadjusted and adjusted relative risk (RR) and $95 \%$ confidence interval $(\mathrm{Cl})$ were calculated. All tests were 2 -sided and $\mathrm{P}$ values $<0.05$ were considered statistically significant. Statistical analyses and data management were performed using SAS 9.4 software (SAS Institute Inc., Cary, NC).

\section{Results}

\section{Patients' characteristics}

A total of 47,097 women newly diagnosed with menstrual syndromes were included in this study. Patients' demographic and clinical characteristics are summarized in Table 1. Patients' mean age was $32.22 \pm 9.15$ years. About three-fourths of patients were aged $15-39$ years, and $81 \%$ lived in urban areas. 
Nearly $53 \%$ of patients have no stable salary or belong to low income group. Infertility was reported by $760(1.61 \%)$ patients, 199 (0.42\%) reported baby delivery, 977 (2.07\%) patients were shown as Ob/Gyn inpatients. 4681 (9.94\%) patients implementation of health preventive measures. 
Table 1

Characteristics of study patients (baseline data)

\begin{tabular}{|c|c|c|}
\hline Variables & $\mathbf{n}$ & $\%$ \\
\hline \multicolumn{3}{|l|}{ Age, years } \\
\hline $15-39$ & 35665 & 75.73 \\
\hline $40-50$ & 11432 & 24.27 \\
\hline Age, years, mean $\pm S D$ & \multicolumn{2}{|c|}{$32.22 \pm 9.15$} \\
\hline \multicolumn{3}{|l|}{ Residence } \\
\hline Rural & 9029 & 19.17 \\
\hline Urban & 38068 & 80.83 \\
\hline \multicolumn{3}{|l|}{ Insurance premium, NT\$ } \\
\hline Fixed premium and dependents & 6111 & 12.98 \\
\hline$<20000$ & 18933 & 40.20 \\
\hline 20000-39999 & 14618 & 31.04 \\
\hline$\geq 40000$ & 7435 & 15.79 \\
\hline \multicolumn{3}{|l|}{ Infertility } \\
\hline Yes & 760 & 1.61 \\
\hline No & 46337 & 98.39 \\
\hline \multicolumn{3}{|l|}{ Baby delivery } \\
\hline Yes & 199 & 0.42 \\
\hline No & 46898 & 99.58 \\
\hline \multicolumn{3}{|l|}{ Obstetric/gynecologic inpatient } \\
\hline Yes & 977 & 2.07 \\
\hline No & 46120 & 97.93 \\
\hline \multicolumn{3}{|c|}{ Implementation of health preventive measures ${ }^{a}$} \\
\hline Yes & 4681 & 9.94 \\
\hline No & 42416 & 90.06 \\
\hline
\end{tabular}

a:Implementation of health preventive measures, such as health exam, Pap smear, or mammography, represents patient's value of prevention 
Table 2 indicate that the number of TCM utilization was 0.69 , and WM utilization was 1.75 within six months after the first menstrual syndrome diagnosis. After half a year (7-12 months), only less than $30 \%$ of the patients are still follow-up, but their TCM utilization was increased to 0.75 , and WM utilization was decreased to 1.60. The observed mean outpatient visits showed an upward trend for TCM and a downward trend for WM (Table 2).

Table 2

Outpatient visits by follow-up period

\begin{tabular}{|c|c|c|c|}
\hline Time periods & No. of patients & No. of visits & $\begin{array}{l}\text { Utilization } \\
\text { (Mean } \pm \text { SD) }\end{array}$ \\
\hline \multicolumn{4}{|l|}{ Traditional Chinese medicine } \\
\hline $1-6$ months of follow-up & 47097 & 29187 & $0.62 \pm 1.80$ \\
\hline 7-12 months of follow-up & 13544 & 10091 & $0.75 \pm 1.98$ \\
\hline $13-18$ months of follow-up & 12720 & 9585 & $0.75 \pm 2.03$ \\
\hline $18-24$ months of follow-up & 12146 & 9937 & $0.82 \pm 2.19$ \\
\hline $25-30$ months of follow-up & 11963 & 9647 & $0.81 \pm 2.15$ \\
\hline $31-36$ months of follow-up & 11525 & 9798 & $0.85 \pm 2.22$ \\
\hline $37-42$ months of follow-up & 11378 & 9967 & $0.88 \pm 2.23$ \\
\hline $43-48$ months of follow-up & 11171 & 10570 & $0.95 \pm 2.36$ \\
\hline 49-54 months of follow-up & 10878 & 10481 & $0.96 \pm 2.31$ \\
\hline $55-60$ months of follow-up & 10310 & 9823 & $0.95 \pm 2.35$ \\
\hline \multicolumn{4}{|l|}{ Western medicine } \\
\hline $1-6$ months of follow-up & 47097 & 78697 & $1.67 \pm 1.69$ \\
\hline 7-12 months of follow-up & 13544 & 21654 & $1.60 \pm 1.67$ \\
\hline $13-18$ months of follow-up & 12720 & 20817 & $1.64 \pm 1.73$ \\
\hline 18-24 months of follow-up & 12146 & 19250 & $1.58 \pm 1.62$ \\
\hline $25-30$ months of follow-up & 11963 & 19223 & $1.61 \pm 1.66$ \\
\hline $31-36$ months of follow-up & 11525 & 18256 & $1.58 \pm 1.64$ \\
\hline $37-42$ months of follow-up & 11378 & 17810 & $1.57 \pm 1.67$ \\
\hline $43-48$ months of follow-up & 11171 & 17692 & $1.58 \pm 1.69$ \\
\hline $49-54$ months of follow-up & 10878 & 17093 & $1.57 \pm 1.74$ \\
\hline $55-60$ months of follow-up & 10310 & 15972 & $1.55 \pm 1.69$ \\
\hline
\end{tabular}




\section{Factors affecting tendency for TCM utilization}

Multivariate Poisson regression analysis revealed that the tendency for TCM utilization increased as the follow-up time increased after controlling for potential confounders (Table 3). Younger women (aged 1539 years), higher economic status, infertility women, and patients who were hospitalized for obstetrics and gynecology were factors that significantly increases the tendency for seeking TCM outpatient services (all $p<0.05$ ). Women with preventive health care value, and women who have baby delivery tend to reduce the use of traditional Chinese medicine. 
Table 3

Tendency for Traditional Chinese Medicine outpatient utilization ${ }^{a}$

\begin{tabular}{|c|c|c|c|c|}
\hline \multirow[b]{2}{*}{ Variables } & \multicolumn{2}{|c|}{ Univariate analysis } & \multicolumn{2}{|c|}{ Multivariate analysis } \\
\hline & RR $(95 \% \mathrm{Cl})$ & $\begin{array}{l}\mathrm{P} \\
\text { value }\end{array}$ & RR $(95 \% \mathrm{Cl})$ & $P$ value \\
\hline \multicolumn{5}{|c|}{$\begin{array}{l}\text { Time periods of follow-up phase, } \\
\text { months }\end{array}$} \\
\hline $1-6$ & 1 [Reference] & & $1[$ Reference] & \\
\hline $7-12$ & $\begin{array}{l}0.92(0.88- \\
0.97)\end{array}$ & 0.002 & $\begin{array}{l}1.17(1.13- \\
1.22)\end{array}$ & $<0.001$ \\
\hline $13-18$ & $\begin{array}{l}0.95(0.90- \\
1.01)\end{array}$ & 0.076 & $\begin{array}{l}1.18(1.13- \\
1.24)\end{array}$ & $<0.001$ \\
\hline $18-24$ & $\begin{array}{l}1.03(0.97- \\
1.10)\end{array}$ & 0.284 & $\begin{array}{l}1.25(1.19- \\
1.31)\end{array}$ & $<0.001$ \\
\hline $25-30$ & $\begin{array}{l}1.03(0.97- \\
1.10)\end{array}$ & 0.267 & $1.24(1.18-1.3)$ & $<0.001$ \\
\hline $31-36$ & $\begin{array}{l}1.11(1.04- \\
1.17)\end{array}$ & 0.001 & $\begin{array}{l}1.29(1.22- \\
1.35)\end{array}$ & $<0.001$ \\
\hline $37-42$ & $\begin{array}{l}1.12(1.06- \\
1.19)\end{array}$ & $<0.001$ & $\begin{array}{l}1.29(1.22- \\
1.36)\end{array}$ & $<0.001$ \\
\hline $43-48$ & $\begin{array}{l}1.22(1.16- \\
1.30)\end{array}$ & $<0.001$ & $\begin{array}{l}1.40(1.34- \\
1.48)\end{array}$ & $<0.001$ \\
\hline $49-54$ & $\begin{array}{l}1.24(1.17- \\
1.32)\end{array}$ & $<0.001$ & $\begin{array}{l}1.41(1.34- \\
1.48)\end{array}$ & $<0.001$ \\
\hline $55-60$ & $\begin{array}{l}1.23(1.15- \\
1.30)\end{array}$ & $<0.001$ & $\begin{array}{l}1.39(1.32- \\
1.47)\end{array}$ & $<0.001$ \\
\hline \multicolumn{5}{|c|}{ Patients' characteristics } \\
\hline \multicolumn{5}{|l|}{ Age } \\
\hline $15-39$ & 1 [Reference] & & 1[Reference] & \\
\hline $40-50$ & $\begin{array}{l}0.91(0.86- \\
0.96)\end{array}$ & 0.001 & $\begin{array}{l}0.93(0.87- \\
0.98)\end{array}$ & 0.009 \\
\hline
\end{tabular}

a: The values in the table are the results after controlling the Western Medicine outpatient utilization (reference $=$ No) during the tracking period.

b. Health prevention practices: Health exam, Pap smear or mammography.

c. Ob: Obstetric, Gyn: Gynecologic 


\begin{tabular}{|c|c|c|c|c|}
\hline & \multicolumn{2}{|c|}{ Univariate analysis } & \multicolumn{2}{|c|}{ Multivariate analysis } \\
\hline Rural & 1 [Reference] & & 1[Reference] & \\
\hline Urban & $\begin{array}{l}1.06(1.01- \\
1.11)\end{array}$ & 0.020 & $\begin{array}{l}1.02 \text { (0.97- } \\
1.07)\end{array}$ & 0.510 \\
\hline \multicolumn{5}{|l|}{ Insurance premium, NT\$ } \\
\hline Fixed premium and dependents & 1 [Reference] & & 1[Reference] & \\
\hline$<20000$ & $\begin{array}{l}1.10(1.03- \\
1.17)\end{array}$ & 0.005 & $\begin{array}{l}1.04(0.96- \\
1.11)\end{array}$ & 0.336 \\
\hline 20000-39999 & $\begin{array}{l}1.24(1.15- \\
1.32)\end{array}$ & $<0.001$ & $\begin{array}{l}1.13(1.05- \\
1.22)\end{array}$ & 0.001 \\
\hline$\geq 40000$ & $\begin{array}{l}1.37(1.27- \\
1.48)\end{array}$ & $<0.001$ & $\begin{array}{l}1.24(1.14- \\
1.35)\end{array}$ & $<0.001$ \\
\hline Health prevention practices ${ }^{b}$, Yes vs. No & $\begin{array}{l}0.81(0.78- \\
0.84)\end{array}$ & $<0.001$ & $\begin{array}{l}0.84(0.80- \\
0.88)\end{array}$ & $<0.001$ \\
\hline Infertility, Yes vs. No & $\begin{array}{l}1.28(1.15- \\
1.43)\end{array}$ & $<0.001$ & $\begin{array}{l}1.49(1.33- \\
1.67)\end{array}$ & $<0.001$ \\
\hline Baby delivery, Yes vs. No & $\begin{array}{l}0.32(0.28- \\
0.36)\end{array}$ & $<0.001$ & $\begin{array}{l}0.16(0.13- \\
0.19)\end{array}$ & $<0.001$ \\
\hline Ob/Gync inpatient, Yes vs. No & $\begin{array}{l}0.62(0.54- \\
0.72)\end{array}$ & $<0.001$ & $\begin{array}{l}1.16(1.01- \\
1.33)\end{array}$ & 0.041 \\
\hline \multicolumn{5}{|c|}{$\begin{array}{l}\text { a: The values in the table are the results after controlling the Western Medicine outpatient utilization } \\
\text { (reference }=\text { No) during the tracking period. }\end{array}$} \\
\hline \multicolumn{5}{|c|}{ b. Health prevention practices: Health exam, Pap smear or mammography. } \\
\hline c. Ob: Obstetric, Gyn: Gynecologic & & & & \\
\hline
\end{tabular}

\section{Factors affecting tendency for WM utilization}

Contrary to TCM, the use of WM outpatient services gradually decreased with as follow-up time increased (Table 4). Women with preventive health care value, infertility, and Ob/Gyn inpatient status were more inclined to seek WM outpatient services (all $p<0.05$ ). Patients with higher economic status or have baby delivery history were tend to reduce the use of WM outpatient services (all $p<0.05$ ). 
Table 4

Tendency for Western Medicine outpatient utilization ${ }^{\mathrm{a}}$

\begin{tabular}{|c|c|c|c|c|}
\hline \multirow[b]{2}{*}{ Variables } & \multicolumn{2}{|c|}{ Univariate analysis } & \multicolumn{2}{|c|}{ Multivariate analysis } \\
\hline & RR $(95 \% \mathrm{Cl})$ & $\begin{array}{l}P \\
\text { value }\end{array}$ & RR $(95 \% \mathrm{Cl})$ & $P$ value \\
\hline \multicolumn{5}{|c|}{$\begin{array}{l}\text { Time periods of follow-up phase, } \\
\text { months }\end{array}$} \\
\hline $1-6$ & 1 [Reference] & & 1[Reference] & \\
\hline $7-12$ & $\begin{array}{l}0.88(0.86- \\
0.90)\end{array}$ & $<0.001$ & $\begin{array}{l}0.87(0.85- \\
0.88)\end{array}$ & $<0.001$ \\
\hline $13-18$ & $\begin{array}{l}0.90(0.89- \\
0.92)\end{array}$ & $<0.001$ & $\begin{array}{l}0.88(0.86- \\
0.90)\end{array}$ & $<0.001$ \\
\hline $18-24$ & $\begin{array}{l}0.87(0.85- \\
0.89)\end{array}$ & $<0.001$ & $\begin{array}{l}0.85(0.83- \\
0.86)\end{array}$ & $<0.001$ \\
\hline $25-30$ & $\begin{array}{l}0.88(0.86- \\
0.90)\end{array}$ & $<0.001$ & $\begin{array}{l}0.85(0.83- \\
0.86)\end{array}$ & $<0.001$ \\
\hline $31-36$ & $\begin{array}{l}0.87(0.85- \\
0.88)\end{array}$ & $<0.001$ & $\begin{array}{l}0.83(0.81- \\
0.85)\end{array}$ & $<0.001$ \\
\hline $37-42$ & $\begin{array}{l}0.86(0.84- \\
0.88)\end{array}$ & $<0.001$ & $\begin{array}{l}0.82(0.81- \\
0.84)\end{array}$ & $<0.001$ \\
\hline $43-48$ & $\begin{array}{l}0.88(0.86- \\
0.90)\end{array}$ & $<0.001$ & $\begin{array}{l}0.84(0.82- \\
0.86)\end{array}$ & $<0.001$ \\
\hline $49-54$ & $\begin{array}{l}0.88(0.86- \\
0.90)\end{array}$ & $<0.001$ & $\begin{array}{l}0.84(0.82- \\
0.86)\end{array}$ & $<0.001$ \\
\hline $55-60$ & $\begin{array}{l}0.87(0.85- \\
0.89)\end{array}$ & $<0.001$ & $\begin{array}{l}0.82(0.80- \\
0.84)\end{array}$ & $<0.001$ \\
\hline \multicolumn{5}{|c|}{ Patients' characteristics } \\
\hline \multicolumn{5}{|l|}{ Age } \\
\hline 15-39 & 1 [Reference] & & 1[Reference] & \\
\hline $40-50$ & $\begin{array}{l}1.06(1.05- \\
1.08)\end{array}$ & $<0.001$ & $1.01(1.00-1.03)$ & 0.082 \\
\hline Residence & & & & \\
\hline
\end{tabular}

a: The values in the table are the results after controlling the Traditional Chinese Medicine outpatient utilization (reference $=$ No) during the tracking period.

b. Health prevention practices: Health exam, Pap smear or mammography.

c. Ob: Obstetric, Gyn: Gynecologi 


\begin{tabular}{|c|c|c|c|c|}
\hline & \multicolumn{2}{|c|}{ Univariate analysis } & \multicolumn{2}{|c|}{ Multivariate analysis } \\
\hline Rural & 1 [Reference] & & 1[Reference] & \\
\hline Urban & $0.98(0.96-1.00)$ & 0.012 & $\begin{array}{l}0.99(0.98- \\
1.01)\end{array}$ & 0.415 \\
\hline \multicolumn{5}{|l|}{ Insurance premium, NT\$ } \\
\hline Fixed premium and dependents & 1 [Reference] & & 1[Reference] & \\
\hline$<20000$ & $\begin{array}{l}0.95(0.93- \\
0.97)\end{array}$ & $<0.001$ & $\begin{array}{l}0.96(0.94- \\
0.98)\end{array}$ & $<0.001$ \\
\hline 20 000-39999 & $\begin{array}{l}0.92(0.90- \\
0.94)\end{array}$ & $<0.001$ & $\begin{array}{l}0.93(0.91- \\
0.95)\end{array}$ & $<0.001$ \\
\hline$\geq 40000$ & $\begin{array}{l}0.89(0.87- \\
0.91)\end{array}$ & $<0.001$ & $\begin{array}{l}0.89(0.87- \\
0.91)\end{array}$ & $<0.001$ \\
\hline Health prevention practices ${ }^{b}$, Yes vs. No & $\begin{array}{l}1.21(1.19- \\
1.23)\end{array}$ & $<0.001$ & $\begin{array}{l}1.22(1.20- \\
1.24)\end{array}$ & $<0.001$ \\
\hline Infertility, Yes vs. No & $1.34(1.3-1.39)$ & $<0.001$ & $\begin{array}{l}1.41(1.37- \\
1.46)\end{array}$ & $<0.001$ \\
\hline Baby delivery, Yes vs. No & $\begin{array}{l}0.91(0.88- \\
0.95)\end{array}$ & $<0.001$ & $\begin{array}{l}0.90(0.87- \\
0.94)\end{array}$ & $<0.001$ \\
\hline Ob/Gync inpatient, Yes vs. No & $\begin{array}{l}2.01(1.95- \\
2.07)\end{array}$ & $<0.001$ & $\begin{array}{l}1.90(1.84- \\
1.96)\end{array}$ & $<0.001$ \\
\hline \multicolumn{5}{|c|}{$\begin{array}{l}\text { a: The values in the table are the results after controlling the Traditional Chinese Medicine outpatient } \\
\text { utilization (reference }=\text { No) during the tracking period. }\end{array}$} \\
\hline \multicolumn{5}{|c|}{ b. Health prevention practices: Health exam, Pap smear or mammography. } \\
\hline c. Ob: Obstetric, Gyn: Gynecologi & & & & \\
\hline
\end{tabular}

\section{Discussion}

Results of the present study revealed that the tendency of TCM utilization increased as the follow-up time increased, whereas the tendency of WM utilization decreased gradually as follow-up time increased. Women's age, economic status, infertility, baby delivery, Ob/Gyn inpatient history and value of prevention were significantly associated with their medical care-seeking behavior.

We found that TCM utilization was only 0.69 and WM utilization was 1.75 within six months after the first menstrual syndrome diagnosis. Unlike some other disease symptoms, symptoms of menstrual discomfort occur frequently and periodically. For women who suffer menstrual discomfort every month, the frequency of related medical utilization is very low. Previous study revealed that most women suffer from menstrual discomfort but only a few will seek medical care $[13,14]$. Participants in another study 
indicated that patient viewed seeking professional treatment was needed only if they felt the pain was too intense and unbearable [15]. It is reasonable to conclude that patients start looking for medical services when symptoms are more severe or unbearable [16].

TCM is widely used in Taiwan and other Asian countries. As part of Complementary and Alternative Medicine, TCM, like western medicine, is a scientific system with complete theory [17]. For better treatment results, the concept of TCM suggests the importance of constitutional adjustments, which will take a long time. Once patients accept the concept of TCM treatment, they will continue to return to the clinic for treatment, and the number of times is often more than at the initial starting point. TCM is usually used frequently by patients who would like to decrease recurrent symptoms and relieve the uncomfortable side effects of treatment [18]. On the contrary, the WM approach put more emphasis on immediate effect that may relieve symptoms quickly. However, menstrual syndromes may recur repeatedly, and patients' expectations may be frustrated, so the number of clinical visits tended to decrease compared with the initial starting point. The author believes that this is the reason why the trend of TCM and WM utilization show an inverted pattern.

In terms of personal characteristics, women of younger ages (15-39 years old), those who have higher economic status, tend to use TCM clinics. The findings of this study are not consistent with those of previous studies. One previous study suggested that medical care-seeking is not associated with age [19]. In addition, older people are more likely to use TCM as their main form of care. However, with the recognition of Chinese medicine by WHO, younger people began to pay attention to the benefits of TCM for improving overall health status and conditioning the body, and they are more likely to actively seek ways to improve their well-being by curing the root of the problem. Therefore, more and more young people choose TCM as their main form of care. Another possible explanation is that older women already have more experience dealing with the menstrual syndromes. Instead of using TCM, they might use other alternative therapy or food remedies to solve these discomforts.

According to TCM, many ways of treatment are available to deal with symptoms, including medications, acupuncture, infrared rays, and so on. Although the NHI program covers TCM and makes these services affordable to all enrollees, many items are still not reimbursable by $\mathrm{NHI}$. As a result, out-of-pocket items of complementary healthcare have become obstacles for low-income patients. The present study revealed that higher economic status was associated with TCM use, which is consistent with the findings of previous research [20].

Longitudinal data (60-months) from the present study revealed that women with medical history of infertility or who were ever hospitalized due to obstetrical/gynecologic disorders would likely use more clinical outpatient services of both TCM and WM. Because both TCM and WM clinical outpatient services are covered by $\mathrm{NHI}$, we reasonably suggested that these women increased outpatient follow-up once they had been diagnosed with the documented medical history. Previous study also indicated that the extension of $\mathrm{NHI}$ benefits coverage led to an increase in the utilization of outpatient services across all income groups among patients [21]. 
On the other hand, the utilization of health preventive services, such as screening tests, had different effects on the use of TCM and WM outpatient services. Women receiving screening tests such as cervical Pap smears and mammography, were less likely to use TCM outpatient services, and were more likely to use WM outpatient services. Previous studies found that patients who underwent gynecological cancer screening were more likely to experience symptom discomfort and would therefore visit outpatient clinics for treatment [13]. In addition, the use of preventive healthcare is a category of WM. Therefore, women who performed these health prevention practices are basically more likely to agree with and therefore seek WM healthcare services.

The present study also found that women who have baby delivery history were tend to reduce the use of outpatient services. After the birth, the uterus and cervix are enlarged, the uterus no longer contracts excessively. When menstruation comes, the menstrual blood is discharged smoothly, and the discomfort of menstrual syndromes may be relieved.

\section{Strengths and limitations}

There are both strengths and limitations to the current study. An important strength of the study is that it used data from a comprehensive, national and high-quality database, which minimized discrepancies and biased studies. In addition, the use of longitudinal data allowed us to conduct long-term research and make it possible to explore the changes in long-term trends. Nevertheless, the present study has several limitations. Although the NHIRD is a large and trusted source of patient data, all analyses are retrospective, which does not rule out selection bias nor allow inference of cause. Also, certain patient data were not known, such as the use of Chinese herbal remedies obtained directly from TCM pharmacies with or without prescriptions from licensed TCM physicians. The study also did not include medical visits that were not covered by the $\mathrm{NHI}$ program. Thus, the frequency of outpatient utilization may have been underestimated. In addition, patients may have used both TCM and WM, or used WM first and then changed to TCM, and these patterns could not be differentiated.

\section{Conclusions}

TCM and WM medical care-seeking patterns differed significantly among women with diagnoses associated with menstrual syndromes. An upward trend was observed for TCM and a downward trend for WM. Medical care-seeking behavior is influenced by age, economic status, infertility, value of prevention, baby delivery and Ob/Gyn inpatient histories. Findings of the present study contribute to increase understanding of patients' medical care-seeking behavior and help to develop appropriate policies to meet their healthcare needs effectively and to reduce inappropriate medical care use.

\section{List Of Abbreviations}

Traditional Chinese Medicine (TCM);

World Health Organization (WHO); 
International Classification of Diseases (ICD);

Western Medicine (WM);

The National Health Insurance (NHI);

National Health Insurance Research Database project (NHIRD);

National Health Research Institute (NHRI);

International Classification of Disease, 9th Revision, Clinical Modification (ICD-9-CM);

Obstetric/gynecologic (Ob/Gyn);

Standard deviation (SD);

New Taiwan Dollars (NTD);

Relative risk (RR);

Confidence interval (Cl)

\section{Declarations}

\section{- Ethics approval and consent to participate}

The study protocol was approved by the institutional review boards of the Taipei City Hospital (TCHIRB1030905) and waived the requirement of informed consent because the dataset is devoid of identifiable personal information. Ethical review board approval is mandatory when applying to use NHIRD data. The Ministry of Health and Welfare in Taiwan is responsible for reviewing applications

\section{- Consent for publication}

Not applicable

\section{- Availability of data and materials}

The data that support the findings of this study are available from NHIRD but restrictions apply to the availability of these data, which were used under license for the current study, and so are not publicly available. Data are however available from the authors upon reasonable request and with permission of National Health Research Institutes, Taiwan. For more information, please visit https://nhird.nhri.org.tw/en/index.html

\section{- Competing interests}


The authors declare that they have no competing interests.

\section{- Funding}

Not applicable

\section{- Authors' contributions}

HCM: Conception and design; Analysis and interpretation of data; Drafting of the manuscript; Data acquisition; Critical revision of the manuscript

GJL: Conception and design; Analysis and interpretation of data; Drafting of the manuscript; Critical revision of the manuscript

LTC: Conception and design; Analysis and interpretation of data; Drafting of the manuscript; Data acquisition; Critical revision of the manuscript

$\mathrm{PH}$ : Drafting of the manuscript; Data acquisition

All authors read and approved the final manuscript.

\section{- Acknowledgements}

Not applicable

\section{References}

1. Cheng HF, Lin YH. Selection and efficacy of self-management strategies for dysmenorrhea in young Taiwanese women. J Clin Nurs. 2011; 20(7-8):1018-25.

2. Tanaka E, Momoeda M, Osuga Y, Rossi B, Nomoto K, Hayakawa M et al. Burden of menstrual symptoms in Japanese women - an analysis of medical care-seeking behavior from a survey-based study. Int J Womens Health. 2013; 6:11-23.

3. Omu FE, Al-Marzouk R, Delles H, Oranye NO, Omu AE. Premenstrual dysphoric disorder: prevalence and effects on nursing students' academic performance and clinical training in Kuwait. J Clin Nurs. 2011; 20(19-20):2915-23.

4. Taylor D. Perimenstrual symptoms and syndromes: Guidelines for symptom management and selfcare. Advanced Studies in Medicine. 2005; 5(5):228-41.

5. Tschudin S, Bertea PC, Zemp E. Prevalence and predictors of premenstrual syndrome and premenstrual dysphoric disorder in a population-based sample. Arch Wom Ment Health. 2010; 13(6):485-94.

6. Delara M, Ghofranipour F, Azadfallah P, Tavafian SS, Kazemnejad A, Montazeri A. Health related quality of life among adolescents with premenstrual disorders: A cross sectional study. Health Qual 
Life Outcomes. 2012; 10(5): 1-5.

7. Schiola A, Lowin J, Lindemann M, Patel R, Endicott J. The burden of moderate/severe premenstrual syndrome and premenstrual dysphoric disorder in a cohort of Latin American women. Value Health. 2011; 14(5):S93-5.

8. Mishell DR, Jr. Premenstrual disorders: epidemiology and disease burden. Am J Manag Care. 2005; 11(16 Suppl):S473-9.

9. Olenja J. Health seeking behaviour in context. East Afr Med J. 2003; 80(2):61-2.

10. Glanz K, Rimer BK, Viswanath K, eds.: Health Behavior and Health Education: Theory, Research, and Practice (4th ed). San Francisco: Jossey-Bass; 2008.

11. Jones CL, Jensen JD, Scherr CL, Brown NR, Christy K, Weaver J. The Health Belief Model as an explanatory framework in communication research: exploring parallel, serial, and moderated mediation. Health Commun. 2015; 30(6):566-76.

12. Oberoi S, Chaudhary N, Patnaik S, Singh A. Understanding health seeking behavior. J Family Med Prim Care. 2016; 5(2):463-4.

13. Farotimi AA, Esike J, Nwozichi CU, Ojediran TD, Ojewole FO. Knowledge, attitude, and healthcareseeking behavior towards dysmenorrhea among female students of a private university in Ogun State, Nigeria. J Basic and Clinical Reproductive Sciences. 2015; 4(1):33-8.

14. Seven M, Güvenç G, Akyüz A, Eski F. Evaluating dysmenorrhea in a sample of Turkish nursing students. Pain Manag Nurs. 2014; 15(3):664-71.

15. Wong LP. Premenstrual syndrome and dysmenorrhea: urban-rural and multiethnic differences in perception, impacts, and treatment seeking. J Pediatr Adolesc Gynecol. 2011; 24(5):272-7.

16. Fang RC, Tsai YT, Lai JN, Yeh CH, Wu CT. The traditional chinese medicine prescription pattern of endometriosis patients in taiwan: a population-based study. Evid Based Complement Alternat Med. 2012; 2012:591391.

17. Expanding Horizons of Healthcare: Five-Year Strategic Plan. https://nccih.nih.gov/sites/nccam.nih.gov/files/about/plans/fiveyear/fiveyear.pdf

18. Pan JC, Tsai YT, Lai JN, Fang RC, Yeh CH. The traditional Chinese medicine prescription pattern of patients with primary dysmenorrhea in Taiwan: a large-scale cross sectional survey. $J$ Ethnopharmacol. 2014; 152(2):314-9.

19. Ferreira ML, Machado G, Latimer J, Maher C, Ferreira PH, Smeets RJ. Factors defining care-seeking in low back pain-a meta-analysis of population based surveys. Eur J Pain. 2010; 14(7):747.e741-7.

20. Shih CC, Liao CC, Su YC, Yeh TF, Lin JG. The association between socioeconomic status and traditional chinese medicine use among children in Taiwan. BMC Health Serv Res. 2012; 12:27.

21. Kim S, Kwon S. The effect of extension of benefit coverage for cancer patients on health care utilization across different income groups in South Korea. Int J Health Care Fi. 2014; 14(2):161-77.

\section{Figures}




\section{Figure 1}

One million longitudinal random sample from National Health Insurance Database in Taiwan

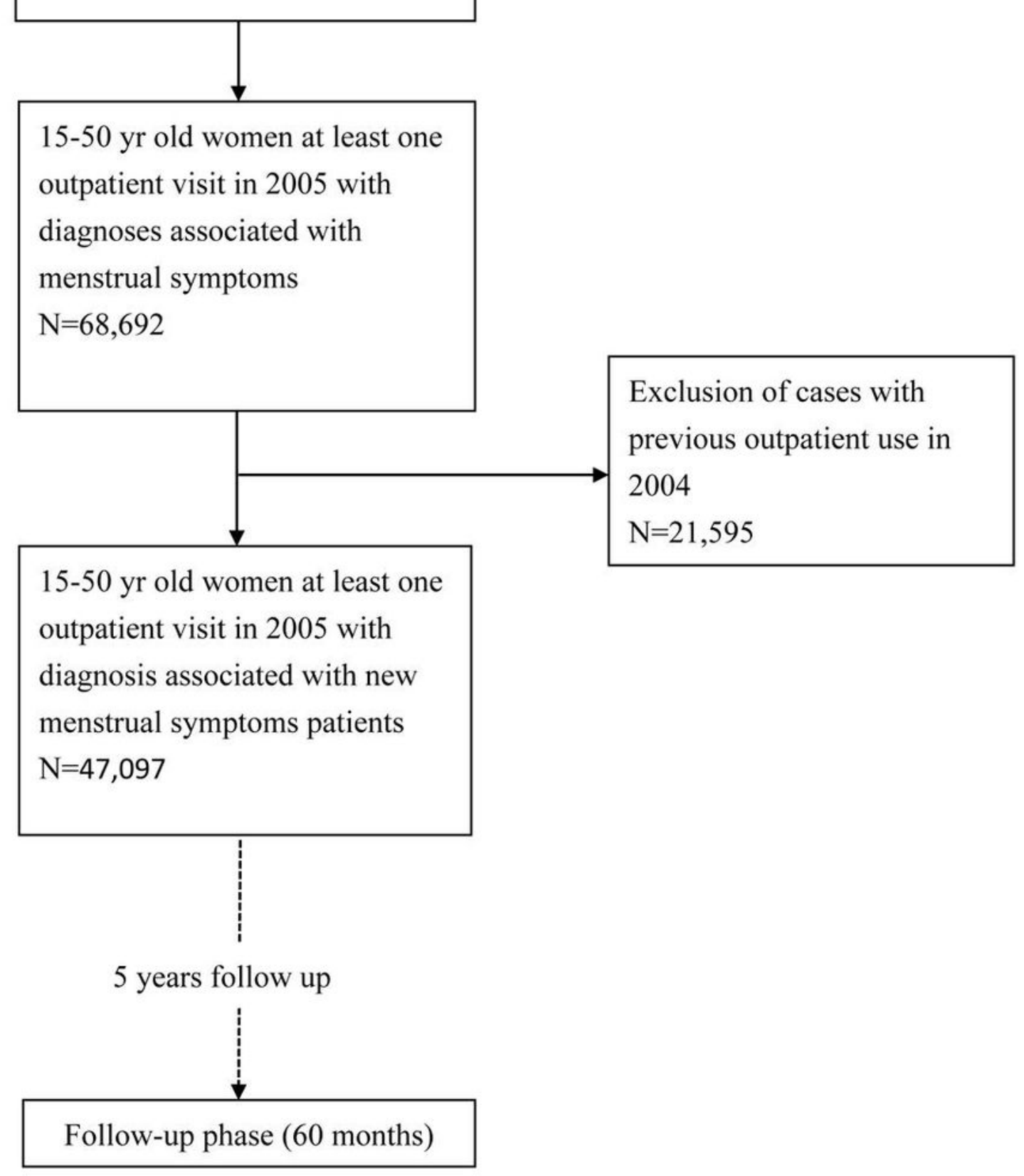

\section{Figure 1}

Study flowchart 